REF - ISSN 1808-0804 Vol. V (3), 54 - 59, 2008

\title{
MELHORANDO A UTILIZAÇÃO DE MEDICAMENTOS NA ATENÇÃO BÁSICA EM UM MUNICÍPIO DO SUDESTE BRASILEIRO
}

\author{
Better use of drugs in basic attention in a brazilian city of southeast \\ SOUZA, D.M.K. ${ }^{1}$; GARBOIS, G.D' ${ }^{1}$; GUIMARÃES, D.A ${ }^{1}$; \\ BARRA, L.G. ${ }^{2}$;YAMAMOTO, C.H ${ }^{2}$; ARAÚJO, A.L.A². \\ ${ }^{1}$ Aluna de graduação da Faculdade de Farmácia e Bioquímica da UFJF. ${ }^{2}$ Professor Orientador; \\ Departamento Farmacêutico, Faculdade de Farmácia e Bioquímica da UFJF.
}

Autor para correspondência e-mail: ailson.luz@ufjf.edu.br

Recebido em 16/10/2008 - Aceito em 20/11/2008

\begin{abstract}
RESUMO: Foi desenvolvido no município de Além Paraíba-MG um projeto com o objetivo de avaliar e melhorar a utilização de medicamentos na atenção básica, com o auxílio da ferramenta $5 \mathrm{~S}$, baseada nos princípios da Qualidade Total. O diagnóstico realizado mostrou que havia condições inadequadas em diversos aspectos do ciclo logístico da Assistência Farmacêutica. Verificou-se, após a realização do estudo, um impacto positivo na organização do serviço farmacêutico. Concluiu-se que as modificações realizadas puderam contribuir para a melhoria de todo o ciclo logístico do medicamento beneficiando a população local.
\end{abstract}

PALAVRAS-CHAVES: Assistência Farmacêutica, Qualidade Total e Medicamentos.

ABSTRACT: It was developed in the city of Além Paraiba, Minas Gerais a work in order to evaluate and improve the use of drugs in primary care, with the help of the $5 \mathrm{~S}$ tool, based on the principles of Total Quality. The diagnosis showed that it had made inappropriate conditions in various aspects of product logistics of Pharmaceutical Assistance. It was after the completion of the study, a positive impact on the organization of the pharmacist. It was concluded that the changes made could contribute to the improvement of the entire cycle of drug logistical benefiting the local population.

KEYWORDS: Pharmaceutical Assistance, Total Quality and Medicines.

\section{INTRODUÇÃO}

A Assistência Farmacêutica, de acordo com o Consenso Brasileiro de Atenção Farmacêutica, pode ser vista como um conjunto de ações desenvolvidas pelo farmacêutico, em conjunto com outros profissionais da área de saúde, voltadas à promoção, proteção e recuperação da saúde, tanto individualmente quanto coletivamente, sempre tendo o medicamento como insumo essencial. A Assistência Farmacêutica visa o acesso e o uso racional deste insumo e envolve ações desde pesquisa e desenvolvimento de fármacos, até o acompanhamento e avaliação do uso pela população, permeando toda a cadeia do medicamento (OPAS, 2002).

A Atenção Farmacêutica, entendida como um modelo de prática profissional desenvolvida no contexto da assistência farmacêutica, possui por finalidade aumentar a efetividade do tratamento medicamentoso, concomitante à detecção de problemas relacionados a medicamentos. $\mathrm{E}$, contempla a interação direta com os pacientes, configurando uma opção mais avançada para o pleno exercício da profissão farmacêutica (SILVA et al., 2008).

O ciclo da Assistência Farmacêutica envolve cinco funções básicas: seleção, programação, aquisição, armazenamento, distribuição e dispensação dos medicamentos (MARIN, 2003).

A seleção é um processo de escolha de medicamentos eficazes e seguros, imprescindíveis ao atendimento das necessidades de uma população, tendo como base as doenças prevalentes. Para orientar essa escolha, a Organização Mundial de Saúde (OMS) disponibiliza a Lista de Medicamentos Essenciais, que deve ser adaptada para cada país, que por sua vez deve elaborar a Relação Nacional de Medicamentos Essenciais (RENAME), documento oficial que serve de referência para os municípios e estados definirem a sua Relação de Medicamentos Essenciais (REMUME) (OMS, 1977). 
Souza, D.M.K. et al./Revista Eletrônica de Farmácia Vol 5(3), 54 - 59, 2008.

Programar medicamentos é estimar as quantidades necessárias para atender as necessidades de uma população por um determinado período de tempo. Vários fatores devem ser considerados ao se fazer uma programação, tais como dados de consumo e demanda, série histórica, perfil epidemiológico, dados populacionais, níveis de atenção, serviços ofertados e recursos financeiros (MARCONDES, 2002).

A aquisição compreende o processo de compras de medicamentos, que no serviço público tem que obrigatoriamente seguir as determinações da Lei de Licitações - Lei n 8.666/ 93 (BRASIL, 1993).

O armazenamento é uma atividade necessária para garantir a qualidade dos medicamentos, através da proteção contra os riscos de alterações físico-químicas e microbiológicas, durante sua estocagem, incluindo recebimento de medicamentos, segurança, conservação e controle de estoque. $\mathrm{O}$ bom armazenamento de medicamentos depende de: temperatura, ventilação e iluminação adequadas, ausência de umidade, limpeza e higiene, normas de segurança, disciplina e organização (BRASIL, 1989).

A distribuição é a entrega de medicamento até o nível local. Compreende o transporte de medicamentos do almoxarifado central para as farmácias locais e deve seguir normas, rotinas e cronogramas institucionais previamente definidos (BRASIL, 1984).

A dispensação é um ato do farmacêutico geralmente como resposta a uma prescrição médica elaborada por um profissional habilitado. Neste ato o farmacêutico orienta e informa o paciente sobre o uso dos medicamentos, dando ênfase ao cumprimento no regime posológico, a influência dos alimentos, as interações medicamentosas, o reconhecimento de reações adversas potenciais e a conservação do produto (BRASIL, 2001).

Com o processo de descentralização da atenção à saúde, cabe ao município uma parcela de responsabilidade crescente, inclusive nas atividades ligadas ao medicamento. A grande falta de farmacêuticos nos países em desenvolvimento, especialmente nos serviços governamentais de saúde, é parte de um problema geral de recursos humanos em saúde, ou seja, um desequilíbrio numérico e qualitativo entre a necessidade (e demanda) e a oferta (OMS, 1993).

A importância de uma política de assistência farmacêutica é inquestionável, tendo como prioridade a reestruturação administrativa das áreas responsáveis pela política de medicamentos como fundamental para uma dinamização dos programas desenvolvidos. Além disso, esses programas podem ajudar a reverter os índices negativos de saúde da população (MEROLA et al., 2008).

Neste sentido foi desenvolvido no município de Além Paraíba-MG, com o apoio da Prefeitura Municipal, um trabalho com o objetivo de avaliar e melhorar as condições de espaço físico, armazenamento, aquisição, dispensação, descarte de medicamentos vencidos ou alterados fisicamente, bem como observar as condições necessárias para conservação de sua qualidade e garantia de sua eficácia no serviço de saúde local.

\section{MÉTODOS}

A cidade Além Paraíba é um município brasileiro do estado de Minas Gerais, localizado na Zona da Mata a uma distância de 380 quilômetros de Belo Horizonte. Através do Censo Demográfico realizado pelo IBGE (2000), a população foi estimada em 30.995 habitantes na zona urbana e 2.587 habitantes na zona rural, totalizando 33.582 habitantes.

Além Paraíba dispõe de uma Agência Transfusional da Fundação HEMOMINAS mantida através de convênio entre este órgão estadual e a prefeitura, prestando serviços pertinentes à hematologia e à hemoterapia, fornecendo bolsas de sangue para hospitais em diversas cidades, como Leopoldina, Cataguases, Muriaé, Miradouro, Recreio, Pirapetinga e principalmente ao hospital municipal.

Para atender ao enorme fluxo de pacientes que recorrem à rede municipal do SUS em Além Paraíba, oriundos da própria cidade, da micro-região mineira (Estrela Dalva, Pirapetinga, Santo Antonio do Aventureiro, Volta Grande) e da micro-região fluminense limítrofe (Carmo e Sapucaia), faz-se necessário a disponibilização de serviços de saúde em quantidade necessária à cobertura da demanda.

O estudo realizado envolveu o diagnóstico inicial sobre as condições da Assistência Farmacêutica local, por meio de visitas ao almoxarifado central e unidades. Em seguida foi realizada uma intervenção visando melhorar as etapas do ciclo onde foram detectados vários problemas.

Foram incluídas cinco Unidades Básicas de Saúde (UBS), oito unidades do Programa de Saúde da Família (PSF), o Centro Municipal de Especialidades Clínicas (CMEC) e o almoxarifado municipal.

Para melhorar a organização dessas locais, a metodologia foi baseada nos princípios do Programa de Qualidade Total 5S, ferramenta criada pelos japoneses e consolidado na década de 50 a partir das palavras: Seiri, Seiton, Seison, Seiketsu e Shitsuke. No Brasil, essas palavras vêm sendo traduzidas para senso de organização, de arrumação, de limpeza, de padronização e de disciplina (OSADA, 1992).

Os objetivos centrais do processo $5 \mathrm{~S}$ consistem em melhorar o ambiente de trabalho, promovendo o bemestar dos funcionários; racionalizar o uso de documentos, materiais e equipamentos; reduzir custos e agilizar o trabalho; facilitar a participação de todos e o inter-relacionamento pessoal, estimulando a execução de tarefas em equipe, e contribuir para a melhoria da imagem da instituição (VANTI, 1999).

O trabalho foi realizado por alunas do curso de Farmácia da Universidade Federal de Juiz de Fora - MG e ocorreu em regime de internato no recesso escolar no município escolhido. Foram desenvolvidas ações de 
Souza, D.M.K. et al./Revista Eletrônica de Farmácia Vol 5(3), 54 - 59, 2008.

promoção à saúde da população local, como parte integrante das ações assistenciais farmacêuticas, tais como: confecção de uma cartilha contendo informações sobre uso de medicamentos, também, foram afixados na farmácia informativos sobre uso correto e descarte de medicamentos, além de informativo referente à validade de receitas de antibióticos. Para facilitar os processos de trabalho e manter a organização estabelecida, foram redigidos manuais de procedimentos para as farmácias e almoxarifado.

\section{RESULTADOS E DISCUSSÃO}

Seleção, programação e aquisição de medicamentos:

Alguns autores atribuem à Assistência Farmacêutica a situação de "estado embrionário" o que leva a um "vazio organizacional" nos serviços de Saúde Pública, incompatível com o modelo desejável. Isto faz com que os estados brasileiros desenvolvam estratégias isoladas de uso de medicamentos com gastos significativos de recursos, cuja eficiência poderia ser aumentada se trabalhassem de forma integrada e sistematizada (PACHECO et al., 1998).

No município de Além Paraíba, o fornecimento de medicamentos essenciais para desenvolver a atenção à saúde da população baseava-se na relação de medicamentos fornecidos pela Fundação Ezequiel Dias (FUNED), Programa Mente Sã, Ministério da Saúde, e compras realizadas pela Prefeitura Municipal para sanar necessidades excepcionais como falta de medicamentos. Sendo assim, a seleção não seguia o parâmetro oficial uma vez que não foi elaborada, tampouco colocada em prática a REMUME.

O almoxarifado organizava a programação e aquisição de medicamentos de acordo com a necessidade das farmácias das UBS's e PSF's. E, ainda detinha o controle das quantidades de medicamentos e correlatos enviados às unidades, porém não lhe era fornecido pelas unidades o estoque atual e nem o consumo desde 0 último pedido.

O município disponibilizava para os PFS's e UBS's, planilhas a serem preenchidas no ato da entrega dos medicamentos contendo quantidade destes enviados, estoque, consumo e quantidade total. Essas planilhas também discriminavam medicamentos do HIPERDIA (Programa de Hipertensos e Diabetes) e medicamentos da farmácia básica. No entanto, apenas nove unidades preenchiam a planilha da farmácia básica, enquanto todas as unidades preenchiam a planilha de medicamentos do HIPERDIA. Isso demonstrou que não havia um controle de estoque eficiente, causando falhas no suprimento dos medicamentos.

Para atender a demanda real de medicamentos do município sugeriu-se a confecção de mapas de consumo semanal e mensal de medicamentos, que deveriam ser entregues às UBS's e PSF's, para facilitar a seleção, programação e aquisição de medicamentos através de cálculo da demanda reprimida. Além disso, para promover um maior controle de medicamentos provenientes do Programa de Saúde Mental (Mente Sã) sugeriuse a criação de mapas de consumo semanal e mensal. Visando o controle dos medicamentos fornecidos pelo Programa Mente Sã, pela FUNED, pelo Ministério da Saúde e por compras realizadas pela Prefeitura Municipal, sugeriu-se a confecção de planilhas de remessas anuais.

\section{Armazenamento:}

O almoxarifado estava desorganizado e o armazenamento era realizado juntamente com outros produtos que não medicamentos ou correlatos, como materiais de limpeza, papelaria e alimentícios. As caixas de medicamentos eram armazenadas no chão, próximas à parede e juntas a outras, havendo grande quantidade de caixas empilhadas. O almoxarifado não possuía telas de proteção contra insetos e roedores e não possuía controle de temperatura e umidade e sofria incidência direta de luz solar.

Os medicamentos eram armazenados em prateleiras de aço de forma aleatória, não organizados em ordem alfabética ou qualquer outro critério. Os medicamentos sujeitos ao controle especial eram armazenados em armários de aço fechados com chave, porém esta tinha livre acesso. Para otimizar o armazenamento utilizouse os princípios da ferramenta $5 \mathrm{~S}$.

Seguindo os princípios relacionados, durante a intervenção realizada foram feitas as seguintes modificações no almoxarifado:

- Organização dos medicamentos em prateleiras e estrados, por ordem alfabética;

- Identificação e armazenamento dos medicamentos sob controle especial em armários de aço com chave, sob os cuidados do responsável pelo almoxarifado;

- Fixação de fichas de identificação contendo os nomes dos medicamentos, suas concentrações e formas farmacêuticas nas prateleiras;

- Separação entre medicamentos e produtos correlatos;

- Mudança do local da recepção, com diminuição do acesso de pessoas ao almoxarifado, e separação em: área administrativa, expedição e armazenamento.

Em relação às farmácias das UBS's e PSF's, foram avaliados visualmente alguns pontos relacionados ao armazenamento de modo a determinar suas condições. Levando em consideração, que na maioria das vezes, 0 local destinado à armazenagem de medicamentos nos centros de saúde não foi projetado para este fim, foram avaliados os seguintes itens: tamanho, ventilação e incidência de luz solar. Assim, oito unidades apresentavam 
Souza, D.M.K. et al./Revista Eletrônica de Farmácia Vol 5(3), 54 - 59, 2008.

espaço suficiente para comportar a quantidade de medicamento existente, nove unidades não apresentavam incidência de luz solar direta nos medicamentos e metade das unidades possuía ventilação apropriada.

É recomendável que o local reservado à armazenagem dos medicamentos destine-se somente para a guarda dos mesmos e sempre separados de outros tipos de materiais (MARIN, 2003). Em doze unidades os medicamentos encontravam-se separados de outros materiais, como material ambulatorial. Já a organização dos medicamentos em prateleiras ou estrados deve permitir a fácil identificação do nome do produto, número do lote e prazo de validade (MARIN, 2003). Em treze unidades os medicamentos encontravam-se dispostos em ordem alfabética e, em outras dez os medicamentos possuíam etiquetas de identificação. Além disso, doze unidades detinham o controle dos lotes de medicamentos vencidos.

\section{Distribuição:}

Os medicamentos e correlatos eram distribuídos de acordo com as listas enviadas ao almoxarifado pelas unidades conforme suas necessidades.

É importante que, para aperfeiçoar a distribuição, seja realizada uma avaliação do estoque da farmácia, observando se há outros medicamentos com estoque insuficiente para o período, devendo ser incluído na solicitação (BRASIL, 1984). Desse modo, sugeriu-se que a distribuição para as farmácias das unidades de saúde deveria ser feita conforme cronograma do município, geralmente quinzenal ou mensal, devendo considerar o número de unidades, disponibilidade de estoque, de transporte, da capacidade de armazenamento da farmácia, de recursos humanos, dentre outros.

Todas essas etapas se refletem nas unidades de saúde, afetando diretamente a qualidade dos serviços de saúde. Se os medicamentos estão freqüentemente em falta, os pacientes sofrem e a equipe perde a motivação. Todos deixam de sentir confiança no sistema de saúde e o atendimento ao paciente perde o seu sentido. 0 suprimento contínuo das unidades com medicamentos de qualidade promove tratamentos efetivos, inspira confiança no posto de saúde e contribui para a satisfação no trabalho e auto-estima entre a equipe (WHO, 1997).

\section{Descarte de medicamentos vencidos ou deteriorados:}

Foi observado que os medicamentos vencidos eram entregues pelo almoxarifado à Vigilância Sanitária para que esta desse o fim correto aos mesmos. De acordo com esse órgão, o descarte dos medicamentos vencidos ou deteriorados era realizado pela prefeitura no "lixão" do município em um local separado para descarte de medicamentos e lixo hospitalar. Nenhuma das unidades visitadas orientava os usuários a retornarem com os medicamentos vencidos para que estas os enviassem ao almoxarifado.

Sugeriu-se a confecção de uma advertência informando a periculosidade do material, e que esta fosse afixada nos sacos de descarte. Recomendou-se que os medicamentos vencidos presentes nas UBS's e PSF's não fossem desprezados na própria unidade, por meio do lixo ou jogando na pia e instalação sanitária, nem permitir que produtos vencidos ou deteriorados fossem reaproveitados, devendo ser encaminhados ao almoxarifado que lhes dariam o correto descarte.

\section{Dispensação:}

A dispensação no município não era realizada de forma adequada, já que na área que abrange as unidades visitadas, não estava presente um profissional habilitado. Pois, só é possível organizar os serviços de apoio necessários, com a imprescindível intervenção farmacêutica. Segundo Amaral et al. (2008), o conceito de intervenção farmacêutica é usado para denominar todas as ações da qual o farmacêutico participa ativamente como nas tomadas de decisão, na terapia dos pacientes e também na avaliação dos resultados.

Como medida provisória, até que a formação de farmacêuticos e técnicos em farmácia atenda às necessidades, muitos países em desenvolvimento precisam depender, em maior ou menor grau, da substituição de recursos humanos, delegando certas funções a profissionais de saúde não-farmacêuticos (MARCONDES, 2004). Portanto, esta etapa do ciclo era realizada por um funcionário especificamente designado para a farmácia em doze dos locais visitados, enquanto em dois destes a dispensação era efetuada por qualquer funcionário da unidade.

\section{Treinamento e atividades educativas:}

Para uma maior facilidade do trabalho e manutenção da organização estabelecida foi confeccionado um manual de rotina para o almoxarifado e as unidades. Ao final do trabalho nesses locais, houve a realização de uma palestra educativa com os funcionários responsáveis pelo almoxarifado e farmácias das unidades conscientizando-os sobre a importância e vantagens da organização e manutenção desta para o serviço.

\section{CONCLUSÃO}

O diagnóstico realizado apontou diversas falhas no processo de utilização dos medicamentos desde a seleção até a dispensação, principalmente em termos de organização do serviço e qualificação do pessoal. 
Souza, D.M.K. et al./Revista Eletrônica de Farmácia Vol 5(3), 54 - 59, 2008.

Conclui-se que projetos como este aproximam os estudantes de Farmácia do paciente e dos outros membros envolvidos na área da saúde. Isso tem como consequência o reconhecimento do papel do farmacêutico como gerenciador das atividades relacionadas ao medicamento. Entretanto, foi visível a carência da cidade em relação à atuação de um farmacêutico nos serviços de saúde. Esse profissional estaria prestando junto ao paciente a Atenção Farmacêutica tão necessária à população de forma a diminuir casos de uso irracional de medicamentos.

As atividades desenvolvidas na organização básica no sistema de saúde de Além Paraíba, com o auxílio do método 5S, conduziram a significantes resultados na Assistência Farmacêutica. No entanto, inúmeras modificações ainda devem ser realizadas de forma que todos os profissionais da área da saúde no local estejam, cada vez mais, envolvidos com o bem estar dos usuários do serviço local.

Existe a necessidade de novos estudos que possam aprofundar aspectos não abordados nesta pesquisa, como aqueles relacionados à utilização de medicamentos pelos usuários. Além disso, torna-se importante, ainda, intervir em outras etapas do ciclo da assistência farmacêutica no município que não puderam ser desenvolvidas, mas foram previamente sugeridas, completando-se assim todo o complexo sistema que envolve o medicamento.

\section{REFERÊNCIAS BIBLIOGRÁFICAS}

AMARAL, M. F. Z. J.; AMARAL, R. G.; PROVIN, M. P. Intervenção farmacêutica no processo de cuidado farmacêutico: uma revisão. Revista Eletrônca de Farmácia, v. 1, p. 60-66, 2008.

BRASIL. Lei Federal no 8.666, 21 jun. 1993. Regulamenta o art. 37, inciso XXI, da Constituição Federal, institui normas para licitações e contratos da Administração Pública e dá outras providências. Diário Oficial da República Federativa do Brasil, Brasília, 1993.

BRASIL. MINISTÉRIO DA SAÚDE. Boas Práticas para Estocagem de Medicamentos. Brasília, 1989.

BRASIL. MINISTÉRIO DA SAÚDE. Almoxarifados Centrais de Medicamentos. Brasília, 1984.

BRASIL. MINISTÉRIO DA SAÚDE. Assistência Farmacêutica na Atenção Básica - Instruções Técnicas para sua organização. Brasília: Gráfica Brasil. p. 114, 2001.

IBGE (Instituto Brasileiro de Geografia e Estatística). Censo Demográfico, 2000 [on line]. Disponível em: www.ibge.gov.br [capturado em 20 de agosto de 2008].

MARCONDES, N. S. P., A Assistência Farmacêutica Básica e o Uso de Medicamentos na Zona Urbana do Município de Ponta Grossa Paraná: estudo de caso. 2002. 157 p. Dissertação (Mestrado) Fundação Oswaldo Cruz, Curso Interinstitucional de Mestrado em Saúde Pública, Universidade Estadual de Ponta Grossa. Rio de Janeiro.

MARIN, N. et al. Assistência farmacêutica para gerentes municipais. Rio de Janeiro: OPAS/OMS, 373 p., 2003.

MEROLA, Y. L.; TERRA, F. S.; COSTA, A. M. D. D. Incentivo à Assistência Farmacêutica na Atenção Básica: Um Projeto em Discussão. Revista Eletrônica de Farmácia, v. 5, n. 1, p. 95-100, 2008.

ORGANIZAÇAO MUNDIAL DE SAUDE (OMS). Seleção de Medicamentos Essenciais. Genebra, p. 7-37, 1977.

ORGANIZAÇÃO MUNDIAL DE SAÚDE (OMS). O papel do farmacêutico no Sistema de Atenção à saúde: Declaração de Tóquio. Genebra, 1993.

ORGANIZAÇÃO PANAMERICANA DE SAÚDE (OPAS). Consenso Brasileiro de Atenção Farmacêutica. Brasília, 24 p., 2002.

OSADA, Takashi. Housekeeping, 5 S's: seiri, seiton, seiso, seiketsu, shitsuke. São Paulo: Instituto IMAN, 1992.

PACHECO, F.; AGUIAR, M. G. G. \& QUEIROZ, A. M. Diagnóstico da Assistência Farmacêutica no Estado da Bahia. Universidade da Bahia. Instituto de Saúde Coletiva. Mimeo, 1998.

SILVA, E. P.; BARRETO, L. F. P.; FREITAS, R. M. Resultados do estudo da dispensação de medicamentos no serviço de farmácia do hospital distrital Gonzaga Mota de Messejana - Ceará. Revista Eletrônica de Farmácia, v. 1, p. 52-59, 2008. 
Souza, D.M.K. et al./Revista Eletrônica de Farmácia Vol 5(3), 54 - 59, 2008.

VANTI, N. Ambiente de qualidade em uma biblioteca universitária: aplicação do $5 \mathrm{~S}$ e de um estilo participativo de administração. Ci Inf, Brasília, v. 28, n. 3, p. 333-339, 1999.

WORLD HEALTH ORGANIZATION (WHO). Manging drug supply: the selection, procurement, distribution and use of pharmaceuticals. USA: Kumarian Press, 1997. 